\section{How to run elections}

SIR - Professor May's article (Nature 5 May, p.16) on electoral procedures for ranking candidates $A, B$ and $C$ is of practical value in a country such as the United States or France which has to elect one person to be president. We must, however, beware of thinking that it has any relevance to the election of parliaments. For that purpose, no method of electing only one person at a time can ensure that the elected body reflects the wishes of the people electing it. Not even that a party ranked first by a substantial majority of the voters will have a majority of the elected members.

The most that Condorcet, Borda or any other system can do in a single-member constituency is to ensure that the member is elected with the consent of at least half the voters. Hence it would be theoretically possible for one party to win all 650 seats in the House of Commons if supported by only one more than half the voters in each constituency. But the same party could have much more support and yet lose the election - by winning a few seats with huge majorities while its opponents slipped into many seats by tiny ones.

To make the great majority of votes effective, and so to make the elected body reflect the opinions of the great majority of the voters, it is essential to elect several members together, for example all those for Bristol or for Bedfordshire as one constituency. Only then is it possible to give representation both to the majority and to any large minority, and to give a large majority more representation than a small one. The worthwhile discussion is on how best to do that.

\section{Tunbridge Wells, Kent, UK}

ENID LAKEMAN

SIR - Robert May's article on voting systems is timely: there is currently discussion in the University of Cambridge about the method of electing members of the Council of the Senate, occasioned by an incident last year when the election of four members had to be disallowed because of an error in a ballot paper. We use the single transferable vote (STV) system specified by Parliament in $1918^{1}$ with the modification, introduced in 1952, that it is also to be used even if there is only a single vacancy.

The ensuing discussion has revealed that many, perhaps most, electors do not understand either the principles of the system or its several virtues. Thus it does not pass the first test of an electoral system, that it has the confidence of the voters.

As May points out, there is no way round the Condorcet (or "voting") paradox when electors place candidates in order of preference. Let us therefore stand the problem on its head and ask not "how can we design a voting system to minimize the occurrence of the paradox?"' but "how can we design a voting system which will maximize the information each elector may contribute subject to the restriction that the voting paradox must not appear?'".

Theorem: The voting paradox can arise if and only if voters are allowed to place in order of preference three or more candidates.

Corollary: If the voting paradox is to be impossible, the most information that any voter can be allowed to communicate is "I prefer each of $A, B, C, \ldots$ to each of $P, Q, R, \ldots$, where $A, B, C, \ldots, P, Q, R$ are the candidates.

The resulting voting system is simply that in which if there are $n$ candidates for $k$ places each voter votes for any subset of the candidates he pleases, and the candidates' total votes are then counted in the ordinary way. Each voter can vary his strategy from voting only for $A$ if the election of $A$ is his sole objective, to, at the other extreme, voting for everyone except $A$ if the nonelection of $\mathrm{A}$ is his sole objective.

A common version of this system is to limit each voter to a maximum of $k$ candidates for whom he may vote; an extreme version is to limit each voter to naming one candidate only, which has a "proportional representation" effect. Somewhere between allowing only one name and allowing any number there should be a simple system which would command wide acceptability in an academic community.

It is therefore interesting to note that by Act of Parliament ${ }^{2}$ in 1854 the University of Oxford was required to elect the members of the Hebdomadal Council (the equivalent of Cambridge's Council of the Senate) by just such a limited-vote system, the limits being prescribed as "for One Vacancy, One Vote [that is, one name]; for Two or Three Vacancies, Two Votes, for Four Vacancies, Three Votes; for Five or Six Vacancies, Four Votes; Provided always, that no Elector shall give more than One Vote for any One Candidate."

However, in 1971 the Hebdomadal Council, calling this system "unnecessarily complicated", proposed one vote for each vacancy in future. The university concurred without a single dissentient voice. It seems indeed that what most people require of a voting system is that they can understand it.

Under the STV system in which voters can select any, or all, of the $n$ candidates and place them in order of preference, the total number of ways of completing a ballot paper is given by $x_{n}$ where

$$
x_{n}=n\left(x_{n-1}+1\right), x_{1}=1
$$

For $n=10$ this is $9,864,100$, and gives an indication of how the STV system provides the voter with too many options. The solution of this recurrence relation involves the partial sum of the common series for $e$; indeed, $x_{n}=$ integral part of $(e . n !-1)$ is, remarkably enough, the exact solution for all values of $n$, even $n=1$.

\section{Gonville and Caius College,}

A.W.F. EDWARDS

\section{Cambridge, UK}

University Elections (Single Transferable Vote) Regulations Statutory Rules and Orders No. 1348 (1918).

Victoriae, 17,18 c.81, XX1.

\section{The wine dark sea}

SIR - Homer's references to a "winecoloured sea" have been a puzzle with such varied "solutions" as the absence of a word for "blue", in their language (manifestly incorrect), through congenital colour-blindness in the Achaeans (patently unlikely) to an outbreak of red-coloured marine algae (possible, but not longlasting). It is curious that a much more earthy explanation has been overlooked.

The original meaning of the word sym-

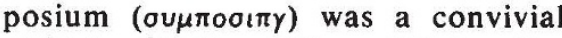
gathering for the exchange of interesting conversation. It is known that the wine was not usually taken pure but only after being diluted with as much as six or even eight parts of water. The geology of the Peloponnesus includes large formations of marble and limestone, so that the ground water must have been alkaline, and where it was sufficiently alkaline it would have raised the $p \mathrm{H}$ enough to change the colour of the wine from red to blue. What this did to the taste is irrelevant inasmuch as everything depends upon what one is used to.

We offer this suggestion to underline the value of communication within the various realms of academia.

R.H. WRICHT

R.E.D. CATTIEY

Vancouver, Canada

\section{Lightning strike}

SIR - The lightning-related phenomenon reported by Burbidge and Robertson (Nature 300, 623-624; 1982) is the only instance I have found, after an extensive search of the literature, which parallels descriptions of amorphous glowing complexes, about the size they describe, seen moving erratically over the surface of hills on the south face of the Himalayas. Paljor Ngodop (Anchorage, Alaska) grew up in the kingdom of Mustang, and in childhood observed such glowing shapes several times. Children used to chase them and throw rocks at them; their elders warned against it, fearing that the objects would turn upon their pursuers.

I never reached Mustang, but in 18 months in the Solu Khumbu and other border points in northern Nepal, I was struck by the daily regularity and long continuation of lightning, at least in spring and summer, on the south side of the highest Himalayan ridge. Lightning-related effects must be correspondingly more common: these are common enough to have been incorporated into the region's folklore, and are categorized as shipa - apparent but nonmetabolic organisms - a grouping also including the yeti and dragons (perhaps colloquialisms for sightings of the rare Himalayan griffon). Tibetan scholars should be alerted to any description or reference in Tibetan literature.

W.S. HoME

Department of Biological Sciences,

University of Alaska,

Fairbanks, Alaska, USA 